\title{
Pengembangan Pendingin Termoakustik dengan Menggunakan Penukar Kalor Tambahan dalam Resonator
}

\author{
Asmara P, Pebriarti A, Setiawan I dan Setio Utomo A B, \\ Jurusan Fisika, Fakultas Matematika dan Ilmu Pengetahuan Alam, \\ Universitas Gadjah Mada, Yogyakarta 55281, Indonesia
}

\begin{abstract}
Abstrak - Telah dilakukan penelitian piranti termoakustik dengan mengamati pengaruh heat exchanger menggunakan berbagai debit cairan dan jenis cairan pada penurunan suhu tandon panas dan tandon dingin.

Hasil yang diperoleh sebagai cairan terbaik yang digunakan adalah air, disamping mudah didapat juga tidak menimbulkan korosi pada pipa tembaga sehingga aliran cairan dalam pipa berjalan dengan lancar dan diperoleh penurunan suhu pada tandon panas sebesar $5,5{ }^{\circ} \mathrm{C}$ serta $1,3{ }^{\circ} \mathrm{C}$ pada tandon dingin. Adapun penurunan suhu optimum tandon panas sebesar $5,4{ }^{\circ} \mathrm{C}$ dan tandon dingin sebesar $1,8{ }^{\circ} \mathrm{C}$ yang terjadi pada saat pipa tembaga dialiri air dengan debit $(2,47 \pm 0,01) \mathrm{mL} / \mathrm{s}$. Terlihat dengan adanya penggunaan heat exchanger berupa pipa tembaga yang dialiri cairan menyebabkan tandon panas mengalami penurunan suhu sehingga tandon panas belum jenuh dan pemompaan kalor dari tandon dingin ke tandon panas tetap stabil (dingin) yang berarti kinerja sistem meningkat.
\end{abstract}

\begin{abstract}
A Research on a Thermoacoustic device for observing the influence of a heat exchanger, in where a liquid rate and a liquid kind are varied, on the temperature decrease of the hot and cool reservoirs has been done. It has been found that the best liquid which is used is water, beside it is easy to find moreover water doesn't cause any corrosion on copper pipes of heat exchanger, so that water in copper pipes can fluently flow. As a result, the temperature decreasing on a hot reservoir is around $5.5{ }^{\circ} \mathrm{C}$ and is around $1.3{ }^{\circ} \mathrm{C}$ on cool reservoir. The optimum temperature decreasing on hot reservoir is about $5.4{ }^{\circ} \mathrm{C}$ and $1.8^{\circ} \mathrm{C}$ on cool reservoir when copper pipe is flowed by a water rate of around $(2.47 \pm 0.01) \mathrm{mL} / \mathrm{s}$. It has been shown that by using a copper pipe in heat exchanger, which is flowed by water, causes a temperature drop on hot reservoir. In other word, hot reservoir has not been saturated yet as a result some heat can continuously move from cool to hot reservoirs, that means the system performance rises.
\end{abstract}

\section{PENDAHULUAN}

Sistem pendingin (AC) umumnya menggunakan bahan pendingin freon padahal freon dijadikan salah satu penyebab kerusakan lapisan ozon di atmosfer bumi. Lebih jauh lagi, hal ini berakibat rusaknya lapisan ozon yang berdampak terjadinya pemanasan global, ketakpastian iklim dunia dan berimplikasi negatif bagi kehidupan di bumi. ${ }^{[1,2,3]}$

Dengan demikian, perlu dikembang-kan suatu sistem pendingin alternatif yang ramah lingkungan, dan salah satunya adalah pendingin termoakustik.

Oleh karena banyak parameter yang menentukan kinerja pendingin termoakustik, maka pada penelitian ini dibatasi yaitu pengaruh adanya penukar kalor (heat exchanger) tambahan dalam resonator. Dengan demikian dapat diselidiki pengaruh kinerja termoakustik dengan adanya penukar kalor tambahan dalam resonator, baik bahan penukar kalor, medium yang digunakan sebagai penukar kalor maupun kecepatan atau debit mediumnya.

\section{STUDI PUSTAKA}

Pustaka acuan yang komprehensif dalam termoakustika telah ditulis menggunakan gelombang berdiri ${ }^{[4]}$. Yazaki $\mathrm{dkk}^{[5]}$ mendemonstrasikan sebuah prototipe pendingin akustik yang menggunakan siklus Stirling. Secara teoretis dan eksperimental tentang karakteristik frekuensi pada pendingin termoakustik telah diperoleh suatu pita frekuensi yang sempit yang membangkitkan osilasi kuat dan menimbulkan efek termoakustik yang signifikan ${ }^{[6]}$. Jensen $\mathrm{dkk}^{[7]}$, memodelkan secara numerik dua pendekatan yang berbeda untuk integrasi gradien suhu di dalam stack termoakustik. Zoontjens $\mathrm{dkk}^{[8]}$ telah mengembangkan desain pendingin termoakusktik, yang selanjutnya dilakukan pemodelan dan optimisasi segmen-segmen inertansi akustik untuk piranti termoakustik dan kinerja sistem secara keseluruhan

Adapun di FMIPA-UGM, sejumlah penelitian telah dilakukan menggunakan resonator silindris dari bahan pipa PVC (panjang $53 \mathrm{~cm}$ dan diameter sekitar $4 \mathrm{~cm} \mathrm{=}$ $1 \frac{112}{2}$ in.), stack dari bahan kertas kardus dan film fotografi, loudspeaker $6 \frac{1}{2}$ in $60 \mathrm{~W} 8 \Omega$ dan penguat audio $60 \mathrm{~W}$ sehingga memberikan kuat (intensitas) bunyi maksimum sebesar $120 \mathrm{~dB}^{[9,10,11]}$, optimasi penentuan posisi stack dalam resonator ${ }^{[12]}$, optimasi diameter resonator $^{[13]}$, dan pengaruh amplitudo bunyi ${ }^{[14]}$ agar kinerja sistem pendingin meningkat.

\section{METODE PENELITIAN}

Siklus proses pendinginan termoakus-tik diilustrasikan pada Gambar 1. 


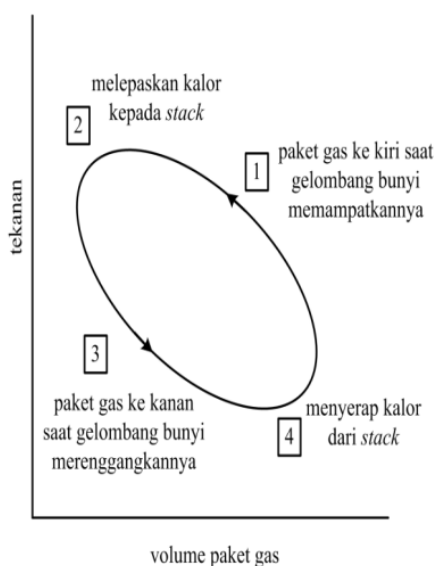

Gambar 1. Diagram P-V yang memperlihatkan empat tahap dalam siklus pendingin (refrigerator) termoakustik $^{[15]}$

Saat gelombang akustik menyebabkan paket gas di dalam stack bergerak ke kiri maka tekanan dalam ruang tersebut akan meningkat dan gas termampatkan. Paket gas yang termampatkan ini sekarang lebih panas daripada dinding stack di dekatnya sehingga gas akan melepaskan kalor ke stack dan menyusutkan volume paket gas tersebut. Saat gelombang melanjutkan siklusnya, paket gas ditarik kembali ke kanan dimana tekanan dalam ruang tersebut lebih rendah. Paket gas menjadi lebih renggang dan lebih dingin dari pada dinding stack di dekatnya, sehingga gas menyerap kalor dari dinding stack untuk mengembang. Siklus ini terus berulang dan efeknya adalah transfer kalor dari bagian kanan ke bagian kiri stack, bagian yang terambil kalornya menjadi bagian dingin (kanan) sedangkan bagian yang dialiri kalor menjadi bagian panas (kiri).

\section{PERALATAN}

Adapun sistem termoakustik lengkap meliputi sistem sumber bunyi, sistem deteksi suhu dan sistem heat exchanger. (Gambar 2)

Sistem sumber bunyi terdiri atas Loudspeaker (+ kotak sebagai penutupnya) dengan merek CUBIG, diameter ring 10 inci, impedance $4 \mathrm{ohm}$, maximum power $400 \mathrm{~W}$. dan. AFG (audio function general) digital model GFG-8016G dengan ketelitian alat $1 \mathrm{~Hz}$ beserta Penguat daya stereo (stereo power amplifier) dengan merek BELL M-900. Sedangkan sistem deteksi suhu terdiri atas dua buah termometer digital dan dua buah termometer batang. Termometer digital yang digunakan disertai sensor suhu tipe LM-35. Termometer digital ini memiliki ketelitian $0,1{ }^{\circ} \mathrm{C}$, sedangkan termometer batang memiliki ketelitian 0,5 ${ }^{\circ} \mathrm{C}$. Sistem Heat Exchanger terdiri atas sebuah pompa air yang digunakan untuk memompa air dari tandon air ke pipa tembaga heat exchanger melalui pipa plastik dan keluaran air dari heat exchanger ke luar sistem/lingkungan.

Adapun bahan-bahan yang digunakan yaitu tabung resonator terbuat dari pipa PVC dengan diameter 5,53 $\mathrm{cm}$ dan panjang pipa $80 \mathrm{~cm}$ (dibagi dalam tiga bagian, panjang $14 \mathrm{~cm}, 11 \mathrm{~cm}$, dan $54 \mathrm{~cm}$ ). Pipa-pipa tersebut dihubungkan dengan dua buah penghubung PVC dengan ketebalan masing masing $0,5 \mathrm{~cm}$. Penghubung PVC pertama dipasang pada pipa berukuran $14 \mathrm{~cm}$ dan $11 \mathrm{~cm}$. Diantara kedua pipa ini diletakkan hot heat exchanger. Kemudian penghubung PVC kedua dipasang antara $11 \mathrm{~cm}$ dan $54 \mathrm{~cm}$. Di dalam pipa berukuran $11 \mathrm{~cm}$ diletakkan stack, sedangkan ujung pipa yang berukuran $54 \mathrm{~cm}$ dihubungkan dengan loudspeaker sedangkan pada ujung pipa $14 \mathrm{~cm}$ ditutup dengan penutup yang terbuat dari PVC ${ }^{[16]}$. Sedangkan stack yang digunakan adalah jenis pelat sejajar yang terbuat dari mika dengan tebal $0,3 \mathrm{~cm}$ dan panjang 10 $\mathrm{cm}$. Pada bagian mika dilekatkan beberapa senar nilon berdiameter $0,1 \mathrm{~cm}$ dan panjang $10 \mathrm{~cm}$ berjarak antar nilon sebesar $2 \mathrm{~cm}$ serta lebar mika stack disesuaikan dengan diameter tabung resonator yang digunakan. Dalam hal ini spasi antar pelat adalah $0,1 \mathrm{~cm}^{[17]}$ (Gambar 3a). Adapun Hot heat exchanger (HHX) sebagai penyerap kalor terbuat dari bahan tembaga berbentuk pipa berdiameter $0,15 \mathrm{~cm}$ dengan bagian tengahnya dibuat bentuk lekukan dengan panjang lekukan 30,5 cm dan tinggi lekukan disesuaikan dengan pipa resonator yang digunakan (Gambar 3b).

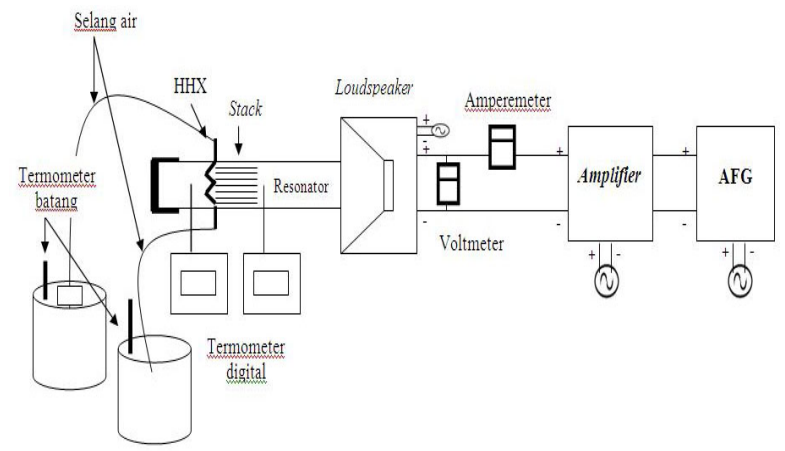

Gambar 2. Set up alat piranti termoakustik ${ }^{[18]}$

Sebelum dimulai eksperimen, frekuensi yang akan digunakan ditentukan terlebih dahulu. Frekuensi resonansi ditentukan melalui perhitungan dengan orde frekuensi $n=1$, tegangan $V=15$ volt (tetap) dan arus $I$ $=2,4$ ampere (tetap). Nilai frekuensi tabung resonator yang diperoleh dari persamaan adalah $108 \mathrm{~Hz}$ dengan $v$ $=349 \mathrm{~m} / \mathrm{s}$ pada suhu kamar. ${ }^{[18]}$
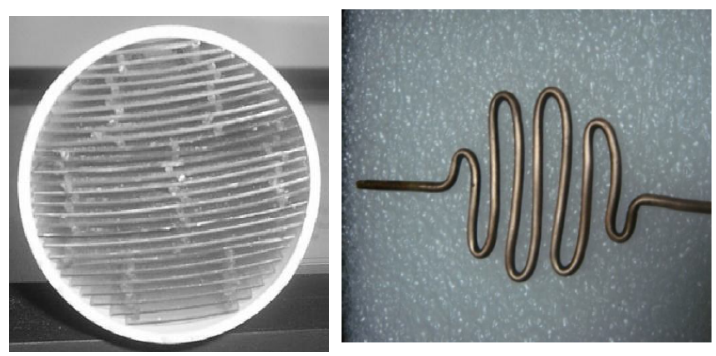

Gambar 3. a). mika stack disesuaikan dengan diameter tabung resonator ${ }^{[17]}, 3 \mathrm{~b}$ Hot heat exchanger 
(HHX) sebagai penyerap kalor terbuat dari pipa tembaga ${ }^{[19]}$

Pengoperasian alat berlangsung selama 50 menit dengan 26 menit pertama hot heat exchanger belum diberi cairan setelahnya hot heat exchanger dialiri dengan cairan sampai menit ke 50. Pada pengukuran laju ini, akan difokuskan pada densitas cairan yang digunakan serta pengaruhnya pada suhu tandon.

Pada saat pengoperasian piranti termoakustik beberapa menit sebelum pipa tembaga heat exchanger dialiri cairan, kedua tandon pada piranti termoakustik mengalami perubahan suhu, dimana pada tandon panas mengalami peningkatan suhu dan pada tandon dingin mengalami penurunan suhu akibat adanya transfer kalor dalam tandon dingin dipindahkan ke tandon panas. (Gambar 4)

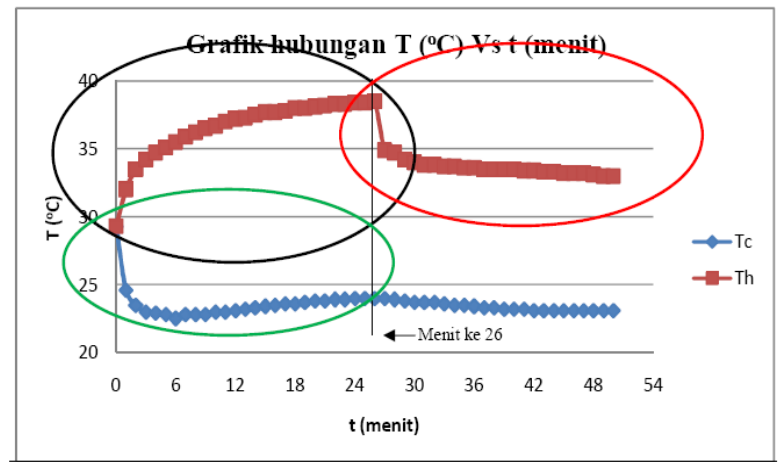

Gambar 4. Grafik suhu vs waktu pada saat hot heat exchanger sebelum dan sesudah hot heat exchanger diberi air pada menit ke $26^{[18]}$

Akan tetapi setelah beberapa menit pengoperasian suhu dalam tandon dingin akan mencapai minimum dan suhu dalam tandon panas mencapai maksimum atau mengalami kejenuhan pada masing-masing tandon. Hal ini berakibat adanya sebagian kalor dalam tandon panas yang mengalir kembali ke tandon dingin sehingga menyebabkan suhu tandon dingin sedikit demi sedikit menjadi naik.

Hal inilah yang mendasari perlunya pembuangan kalor dari tandon panas ke luar dari sistem piranti termoakustik agar suhu pada tandon panas tidak jenuh sehingga tidak ada aliran kalor balik dari tandon panas ke tandon dingin dan suhu pada tandon dingin tetap dingin.

Pendinginan hot heat exchanger dengan menggunakan cairan memberikan perubahan terhadap laju pendinginan dan pemanasan tandon. Hot heat exchanger dibuat dari bahan tembaga yang memiliki kapasitas panas tinggi dan konduktivitas termal yang besar sehingga mampu menyerap dan melepaskan kalor. Hot heat exchanger yang digunakan berbentuk uliran supaya pipa tembaga yang berada di dalam tandon panas cukup banyak menyerap kalor. Sedangkan cairan yang digunakan untuk mendinginkan hot heat exchanger berupa : air, larutan garam, dan alkohol.

Pada saat hot heat exchanger dialiri cairan, suhu pada tandon panas relatif menurun, hal ini disebabkan karena cairan mampu membawa kalor dan membuangnya ke lingkungan.

Hasil penelitian menunjukkan bahwa penurunan suhu terbesar terjadi pada saat hot heat exchanger dialiri cairan yang memiliki densitas $\rho=0,9968 \mathrm{~g} / \mathrm{cm}^{3}$ yaitu air dengan penurunan suhu yang diperoleh sebesar $5,5{ }^{\circ} \mathrm{C}$ terjadi pada tandon panas dan $1,3{ }^{\circ} \mathrm{C}$ terjadi pada tandon dingin. Besarnya nilai kapasitas panas yang dimiliki air mempengaruhi besarnya penurunan suhu yang terjadi pada kedua tandon. ${ }^{[18]}$

Gambar 5 merupakan grafik pengoperasian alat selama 30 menit tanpa dan dengan cairan berdebit $(2,45$ $\pm 0,01) \mathrm{mL} / \mathrm{s}$.

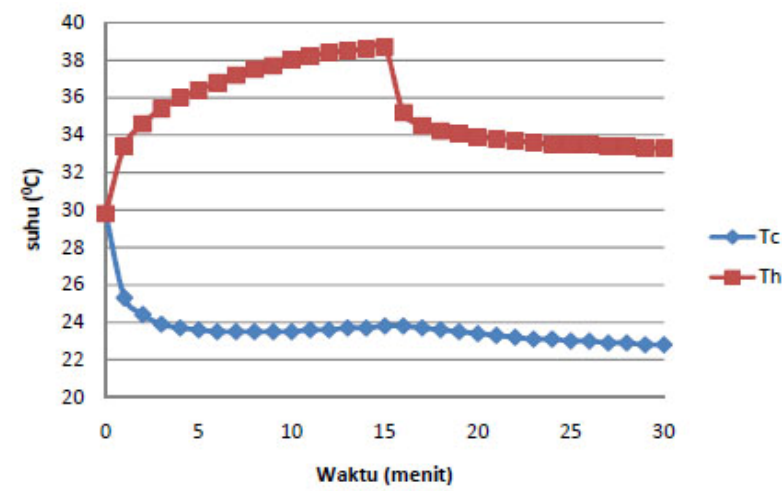

Gambar 5. Grafik suhu vs waktu pengoperasian piranti termoakustik selama 30 menit dengan heat exchanger tanpa dan dengan cairan ${ }^{[19]}$

Setelah pengoperasian piranti termoakustik selama 15 menit berikutnya, heat exchanger pipa tembaga dialiri cairan air dan debit tertentu, sehingga pipa tembaga dan cairan yang dialirkan akan menyerap panas pada tandon panas dan dibuang keluar sistem.

Terlihat bahwa suhu pada tandon panas akan langsung mengalami penurunan hingga beberapa derajat Celcius, sedangkan pada tandon dingin tidak langsung mengalami penurunan suhu tetapi beberapa saat setelah pemberian cairan pada pipa tembaga heat exchanger.

Hal ini disebabkan karena kalor pada tandon panas diserap langsung oleh pipa tembaga dan cairan yang dialirkan sehingga suhu pada tandon panas akan langsung turun, sedangkan pada tandon dingin masih dalam proses pemompaan kalor dari tandon dingin ke tandon tandon panas. Jika pemompaan kalor dari tandon dingin ke tandon panas berlangsung stabil maka suhu tandon dinginpun akan semakin turun juga.

Terlihat pada Gambar 6 mulai menit ke 10 sampai menit ke 15 terjadi kenaikan suhu yang cenderung 
semakin bertambah pada tandon dingin. Ketakstabilan ini diakibatkan adanya arus balik kalor dari tandon panas ke tandon dingin yang tidak mampu diimbangi oleh pemompaan kalor dari tandon dingin ke tandon panas dan hal ini yang mengakibatkan suhu pada tandon dingin semakin bertambah.

Dengan adanya cairan pada heat exchanger, maka sebagian kalor pada tandon panas akan terserap dan dibuang keluar sistem sehingga tidak mengalir balik ke tandon dingin.

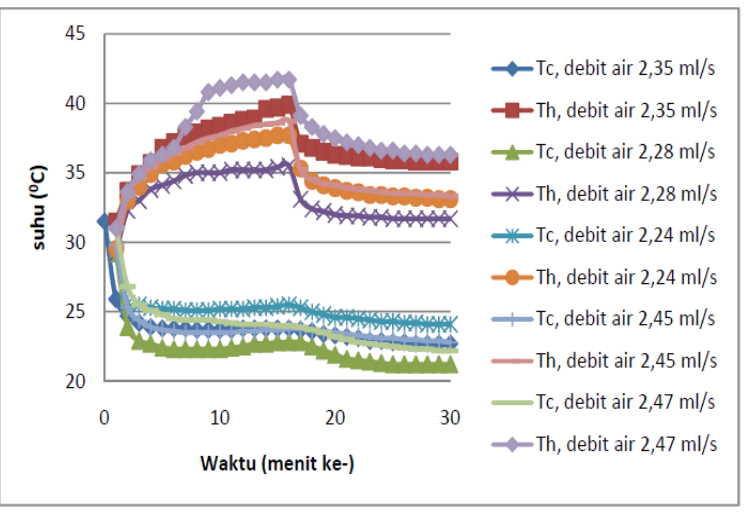

Gambar 6. Grafik suhu vs waktu pengoperasian pada piranti termoakustik dengan berbagai debit $\operatorname{air}^{[19]}$

Hal ini ditunjukkan pada suhu tandon panas yang menurun atau dengan lain kata suhu pada tandon panas sudah tidak jenuh lagi. Akibat lebih jauh lagi pembuangan kalor dari tandon dingin ke tandon panas akan berlangsung dengan baik tanpa adanya arus kalor balik, sehingga sistem akan stabil (dingin) dengan suhu pada tandon dingin tidak bergeser naik.

Dilain pihak menggunakan air, terlihat bahwa penurunan suhu pada tandon panas sudah cukup baik karena kebanyakan hasil menunjukkan bahwa semakin besar debit air semakin besar pula penurunan suhu pada tandon panas. Hanya saja pada debit $(2,24 \pm 0,01) \mathrm{mL} / \mathrm{s}$ terjadi penurunan suhu yang cukup besar melebihi penurunan suhu tandon panas pada debit air yang lebih besar.

Pada tandon dingin penurunan suhu yang terjadi tidak linier terhadap semakin besarnya debit air, namun tetap terlihat bahwa pada debit terbesar menghasilkan penurunan suhu terbesar di tandon dingin. Pada dasarnya, semakin besar debit yang dialirkan semakin besar pula penurunan suhu pada tandon dingin dan tandon panas. Akan tetapi terkadang tidaklah demikian realitasnya, hal ini dikarenakan adanya beberapa faktor yang mempengaruhi hasil penurunan suhu pada kedua tandon tersebut, antara lain kapasitas panas, kelancaran aliran dan sebagainya.

\section{KESIMPULAN}

Kesimpulan yang diperoleh dari penelitian ini adalah bahwa adanya penggunaan heat exchanger berupa pipa tembaga yang dialiri oleh cairan pada tandon panas menyebabkan penurunan suhu pada tandon panas sehingga tandon panas tidak jenuh sehingga pemompaan kalor dari tandon dingin ke tandon panas tetap stabil dan tidak terjadi arus kalor balik.

Disamping itu penurunan suhu optimum pada kedua tandon terjadi pada debit terbesar, dengan viskositas dan densitas yang lebih kecil. Adapun penurunan suhu optimum terjadi pada saat pipa tembaga dialiri air dengan debit $(2,47 \pm 0,01) \mathrm{mL} / \mathrm{s}$, dan penurunan suhu pada tandon panas sebesar $5,4{ }^{\circ} \mathrm{C}$ dan tandon dingin sebesar $1,8^{\circ} \mathrm{C}$.

\section{DAFTAR PUSTAKA}

[1] Anonim, 2007a, Perlindungan Lapisan Ozon, Kementrian Negara Lingkungan hidup, http://ozon.menlh.go.id diakses pada tanggal 10 April 2007.

[2] Anonim, 2007b, Thermoacoustics, Los Alamos National Laboratory, http://www.phys.tue.nl/lt/workshop/workshop.html diakses pada tanggal 24 Januari 2007.

[3] Anonim, 2007c, First International Workshop on Thermoacoustics, Technische Universiteit Eindhoven and the Acoustical Society of America, http://www.lanl.gov/projects/thermoacoustics/ diakses pada tanggal 4 Februari 2007.

[4] Swift, G.W., 2002, Thermoacoustics: A Unifying Perspective for Some Engines and Refrigerators, Los Alamos National Laboratory, Acoustical Society of America Publications.

[5] Yazaki, T., Biwa, T., dan Tominaga, A., 2002, A Pistonless Stirling Cooler, Appl. Phys. Lett. 80(1), 157-159.

[6] Tu, Q., Gusev, V., Bruneau, M., Zhang, C., Zhao, L., dan Guo, F., 2006, Experimental and Theoretical Investigation on Frequency Characteristic of Loudspeaker-driven Thermoacoustic Refrigerator, Cryogenics 45, 739-746.

[7] Jensen, C., Raspet, R. dan Slaton, W., 2006, Temperatur Gradient Integration in Thermoacoustic Stacks, App. Acoust. 67, 689-699.

[8] Zoontjens, L., Howard, C.Q., Zander, A.C., dan Cazzolato, B.S., 2005, Development of a Low-Cost Loudspeaker-Driven Thermoacoustic Refrigerator, Proceeding of Acoustics, 9-11 November 2005, Busselton, Western Australia.

[9] Ikhsan S., Agung B.S.U, Andi R.W., Guntur M., 2005, Rancang Bangun Piranti Termoakustik sebagai Pendingin dan Pemanas Udara secara Simultan, Laporan Penelitian Antar Bidang Ilmu 2005, FMIPA, UGM, Yogyakarta.

[10] Ikhsan S., Agung B.S.U., Andi R.W., dan Guntur M., 2007, Rancang bangun piranti termoakustik sebagai pemompa kalor, Sigma Vol.10 No. 1, hal. 25-33.

[11] Elyanita MS, Setiawan I dan Setio Utomo A B, 2007, Pengaruh Peubah frekuensi dan posisi stack bahan kardus terhadap peubah suhu pada sistem 
termoakustik, Jurnal Fisika Indonesia No. 33 Vol.

XI, Edisi Agustus 2007. ISSN: 1410-2994

[12] Romdhiah, I. Setiawan, dan Setio Utomo A B., 2006, Pengaruh Variasi Posisi Stack dan Frekuensi Gelombang Bunyi Terhadap Perbedaan Suhu pada Sistem Termoakustik dengan Bahan Stack Film, Jurnal Fisika Indonesia No. 31 Vol. X, Edisi Desember 2006. ISSN: 1410-2994

[13] Sampurna D, Setiawan I dan Setio Utomo A B, 2007, Studi eksperimen untuk mengetahui pengaruh diameter tabung resonator silindris terhadap kinerja piranti termoakustik, Jurnal Fisika Indonesia No. 33 Vol. XI, Edisi Agustus 2007. ISSN: 1410-2994

[14] Zulheldi, Ikhsan Setiawan dan Setio Utomo A B, 2006, Pengaruh Intensitas Bunyi, Jarak Letak Stack dan Diameter Tabung Resonator pada Piranti Termoakustik, Jurnal Fisika Indonesia No. 31 Vol. X, Edisi Desember 2006. ISSN: 1410-2994

[15] Russell, D.A. dan Weibull, P., 2002, Tabletop Thermoacoustic Refrigerator for Demonstration, Am. J. Phys. 70, 1231-1233.

[16] Ma'rifah, L.K, 2009, Optimalisasi Diameter Tabung Resonator Silindris Dan Daya Loudspeaker Terhadap Penurunan Suhu Pada Sistem Pendingin Termoakustik, Skripsi S1, Jurusan Fisika, FMIPA UGM, Yogyakarta.

[17] Naibaho, K. E. J. A, 2009, Studi Pengaruh Tegangan Loudspeaker Dan Ketebalan Pelat Stack Sejajar Terhadap Perubahan Suhu Pada Resonator Silindris Ujung Tertutup Piranti Termoakustik, Skripsi S1, Jurusan Fisika, FMIPA UGM, Yogyakarta.

[18] Pebriarti A, 2011, Pengaruh Berbagai Densitas Cairan Pada Heat Exchanger Terhadap Penurunan Suhu Dalam Piranti Termoakustik, Skripsi S1, Jurusan Fisika FMIPA UGM, Yogyakarta

[19] Asmara P, 2011, Pengaruh Pipa Tembaga berisi Cairan yang mengalir sebagai Heat exchanger pada Piranti Termoakustik, Skripsi S1, Jurusan Fisika FMIPA UGM, Yogyakarta. 